\title{
ASTA - A method for multi-criteria evaluation of water supply technologies to Assess the most SusTainable Alternative for Copenhagen
}

Godskesen, Berit; Hauschild, Michael Zwicky; Albrechtsen, Hans-Jørgen; Rygaard, Martin

Published in:

Science of the Total Environment

Link to article, DOI:

10.1016/j.scitotenv.2017.11.018

Publication date:

2018

Document Version

Peer reviewed version

Link back to DTU Orbit

Citation (APA):

Godskesen, B., Hauschild, M. Z., Albrechtsen, H-J., \& Rygaard, M. (2018). ASTA - A method for multi-criteria evaluation of water supply technologies to Assess the most SusTainable Alternative for Copenhagen. Science of the Total Environment, 618, 399-408. https://doi.org/10.1016/j.scitotenv.2017.11.018

\section{General rights}

Copyright and moral rights for the publications made accessible in the public portal are retained by the authors and/or other copyright owners and it is a condition of accessing publications that users recognise and abide by the legal requirements associated with these rights.

- Users may download and print one copy of any publication from the public portal for the purpose of private study or research.

- You may not further distribute the material or use it for any profit-making activity or commercial gain

- You may freely distribute the URL identifying the publication in the public portal 
1 ASTA - a method for multi-criteria evaluation of water supply technologies to Assess the most

2 SusTainable Alternative for Copenhagen

4 B. Godskesen ${ }^{\mathrm{a}, *}$, M. Hauschild ${ }^{\mathrm{b}}$, H.-J. Albrechtsen ${ }^{\mathrm{a}}$, M. Rygaard ${ }^{\mathrm{a}}$

$5{ }^{a}$ Technical University of Denmark, Department of Environmental Engineering, Bygningstorvet,

6 Building 115, 2800 Lyngby, Denmark ("Corresponding author,e-mail:berg@env.dtu.dk)

$7{ }^{\mathrm{b}}$ Technical University of Denmark, Department of Management Engineering, Produktionstorvet, $8 \quad$ Building 424, 2800 Lyngby, Denmark

10 Abstract

11 Utilities in larger cities have to make complex decisions planning future investments in urban water

12 infrastructure. Changes are driven by physical water stress or political targets for environmental

13 water flows e.g. through the implementation of the European water framework directive. To include

14 these environmental, economic and social sustainability dimensions we introduce a novel multi-

15 criteria assessment method for evaluation of water supply technologies. The method is presented

16 and demonstrated for four alternatives for water supply based on groundwater, rain- \& stormwater

17 or seawater developed for augmenting Copenhagen's current groundwater based water supply. To

18 identify the most sustainable technology, we applied rank order distribution weights to a multi-

19 criteria decision analysis to combine the impact assessments of environment, economy and society.

20 The three dimensions were assessed using 1) life-cycle assessment, 2) cost calculations taking

21 operation and maintenance into account and 3) the multi-criteria decision analysis method 
22 Analytical hierarchy process. Specialists conducted the life-cycle assessment and cost calculations and the multi-criteria decision analyses were based on a stakeholder workshop gathering

24 stakeholders relevant for the specific case. The workshop reached consensus on three sets of ranked

25 criteria. Each set represented stakeholder perspectives with first priority given to one of the three sustainability dimensions or categories. The workshop reached consensus and when the highest weight was assigned to the environmental dimension of sustainability then the alternative of 'Rain\& stormwater harvesting' was the most sustainable water supply technology; when the highest weight was assigned to the economy or society dimensions then an alternative with 'Groundwater

30 abstraction extended with compensating actions' was considered the most sustainable water supply

31 technology. Across all three sets of ranked weights, the establishment of new well fields is considered the least sustainable alternative.

33 Keywords: Analytical hierarchy process; Desalination; Economic assessment; Freshwater

34 withdrawal impact; Groundwater abstraction; Life-cycle assessment; Multi-criteria decision

35 analysis; Rain- and stormwater harvesting; Ranked order distribution; Water supply 


\section{Introduction}

37 The impact of withdrawing water is high on the agenda both regarding a worldwide focus on the

38 limited freshwater availability (Alcamo \& Gallopín, 2009; European Environment Agency, 2012),

39 legislation (European Union, 2000) and the sustainable development goals (UN, 2015) emphasizing

40 the importance of protecting freshwater environments and ecosystems. The European water

41 framework directive (EU-WFD) is implemented in the EU-Member states by the national river

42 basin management plans which among other parameters regulate the water flow requirements for

43 water courses and the available amount of water in each freshwater compartment, including

44 groundwater bodies. In Denmark the implementation of the EU-WFD has revealed that

45 groundwater is not as abundant a resource as often assumed (European Environment Agency, 2007)

46 since the river basin management plans for Denmark require that $65 \%$ of the renewable

47 groundwater resource should be allocated to the freshwater environments (Danish Nature Agency, 48 2011).

49 In Europe on average $70 \%$ of the drinking water is produced from groundwater (Navarrete et al.,

50 2008) and in Denmark groundwater is currently the only source used for centralized water supply

51 and only very few local rainwater harvesting systems exist (Rygaard et al., 2009). Therefore, the

52 implementation of the EU-WFD has forced the water utility in Copenhagen, HOFOR, to explore

53 new approaches to maintain abstraction licenses or new water resources for water production in

54 order to meet the water demand of the Capital City, Copenhagen. Since water production in

55 Copenhagen today solely relies on groundwater, the impacts on the groundwater resources and

56 natural environments such as water flow in watercourses has to be included in environmental

57 evaluations of alternative water resources. 
58 Besides groundwater resources, other criteria are important to include in the decision making

59 process of how to identify the most suitable or, as in our case, the most sustainable water supply

60 alternative for the City.

61 The term "sustainable development" is often quoted from the Brundtland Commission (WCED,

62 1987) as: "development that meets the needs of the present generation without compromising the

63 ability of future generations to meet their own needs". In 1992 this definition of sustainable

64 development was concretized a step further as a balance of three dimensions: environmental

65 protection, economic growth, and social development (UNEP, 1992). Therefore, not only the

66 impact on the water courses has to be considered but criteria representing these three dimensions -

67 environment, economy and society - also have to be included in the development of decision

68 support. This can be achieved by life-cycle assessment (LCA), cost-benefit analysis (CBA) and

69 multi-criteria decision analysis (MCDA) with involvement of central stakeholders. The goal for our

70 investigation was to develop a decision support system which incorporates criteria for all three

71 sustainability dimensions and determines the trade-off between various criteria. Thus, providing the

72 decision maker with a decision support material where weighting and trade offs are carried out and

73 are not left for manual subjective judgement. The resulting decision support system "Assessing the

74 most SusTainable Alternative” (ASTA) thus integrates LCA, CBA and MCDA into one joint

75 decision support tool.

76 Multi-criteria decision analysis (MCDA) supports decision making in the choice between several

77 options or cases based on evaluations involving several different criteria. MCDA has been applied

78 in many cases within water management as documented by Hajkowicz \& Collins (2007) who listed

79113 studies on MCDA in water management published since 1973. The purpose of using MCDA in

80 water management are various, e.g. policy evaluation, strategic planning, infrastructure selection. 
81 Within the water sector MCDA has thus been used to identify the optimal solution by a) elicit scores to criteria and b) determine the capacity for trade-offs between criteria: 1) Some MCDA methods are applicable for eliciting scores for alternative water management cases based upon predefined criteria, if other more quantitative evaluation methods such as LCA or CBA are not within hand (Jaber \& Mohsen, 2001; Makropoulos et al., 2008). 2) Other MCDA methods are designed to assign weights to criteria based on their relative importance to central stakeholders (Goodwin \& Wright, 2009; Lai et al., 2008; Rowley et al., 2012). For instance Sombekke et al., 1997) used MCDA to combine the results of an LCA with other criteria (water quality and public health, reliability, landscape, economy, etc.) when choosing between two types of water treatment for reducing water hardness at the waterworks (central softening). MCDA methods are also recommended for combining multiple criteria in the framework for decision support systems aimed at making a sustainable decision as described in the work of Lundie et al. (2006) and Halog \&

93 Manik (2011).

We developed a unique integration of quantitative evaluation tools (LCA, Freshwater Impact Assessment and Cost Assessment) and more qualitative assessment of societal impacts. At a stakeholder workshop we used the Analytical Hierarchy Process (AHP) (Saaty, 2006) to convert the assessment of the social dimension into quantitative scores. The combining of the sustainability dimensions, e.g. in a DSS is necessary to identify the optimal and most sustainable solution in a study. The same approach is found in studies planning sustainable community water systems when urbanization is increasing (Schoen et al., 2017; Rygaard et al., 2014) also aiming at combining various criteria or metrics. In our case, we used the above-mentioned evaluation tools and integrated the assessments in a multi-criteria workshop with representatives from a broad range of stakeholders with interest in urban water supply. To acknowledge different preferences, the 
assessment method was designed to assign individual stakeholder weights to qualitative criteria as well as the weighting between the three sustainability dimensions: environment, economy and societal impacts. Our method was demonstrated in a test case built on four suggested alternatives for water supply to Copenhagen, Denmark.

\section{Material and methods}

\subsection{Study area and alternatives}

Four water supply alternatives have been identified for Copenhagen that can, either alone or in combination with the existing groundwater abstraction (A0), constitute Copenhagen's future water supply fulfilling the EU-WFD requirements. The present water supply method and the alternatives are (Figure 1): A0: 'Base alternative' (the current situation), A1: 'Rain- \& stormwater harvesting', A2: 'Compensating actions', A3: 'New well fields', A4: 'Desalination'. A list of the alternatives' life-cycle inventory is found in Supplementary material.

\subsubsection{Alternative A0: Base Alternative (the current situation)}

A groundwater volume of approximately 50 million $\mathrm{m}^{3}$ is annually abstracted to supply the area of Greater Copenhagen (population of 1.28 million) with drinking water. The water is abstracted from groundwater sources mainly located outside the city and requires only treatment in terms of aeration and rapid sand filtration before distribution. The water abstraction, treatment and distribution consume as little as $0.27 \mathrm{kWh}$ per $\mathrm{m}^{3}$ drinking water. The groundwater originates from chalk aquifers and has a hardness of $362 \mathrm{mg} / \mathrm{L}$ as $\mathrm{CaCO}_{3}$ categorized as very hard drinking water (US Geological Survey, 2012). This high hardness causes indirect environmental impacts in the households when water is consumed (Godskesen et al., 2012) and these impacts are included in the comparison with the alternatives with a lower water hardness leading to lower environmental 
impacts (A1 and A4). After use wastewater is transported via combined sewers to the municipal wastewater treatment plants where it is treated before discharge to the Sea (Øresund).

\subsubsection{Alternative A1: Rain- \& stormwater harvesting}

129 Rain- and stormwater is considered harvested from an urban area of $68,500 \mathrm{~m}^{2}$ (where roof area is $13020,200 \mathrm{~m}^{2}$ and main road area is $8,500 \mathrm{~m}^{2}$ the rest is primarily smaller roads, pavements and green 131 areas) populated by 1,000 residents and 200 employees. Rainwater is collected from the roofs and 132 led to an underground basin $\left(750 \mathrm{~m}^{3}\right)$. Stormwater from the main road is collected in large pipes 133 (diameter 1,000 $\mathrm{mm}$ ) and led to a basin with a clarifier and pumping station controlling the flow.

134 The clarifier separates oils from the water before it passes through a dual porosity filter where the stormwater by gravity flows through a filter of $\mathrm{CaCO}_{3}$ particles to adsorb and remove suspended solids, heavy metals and PAHs (Jensen, 2009). Afterwards the treated stormwater is mixed with rainwater and stored in a basin. The water is UV-treated prior to distribution back to the residential 138 and office buildings from where the rainwater was originally collected. After treatment the water

139 hardness is $145 \mathrm{mg} / \mathrm{L}$ as $\mathrm{CaCO}_{3}$ (Jensen, 2009). The water is considered of non-potable quality and 140 is used for toilet flushing and clothes washing. The area has combined sewers, which is the typical 141 situation in most parts of Copenhagen, and the reduction of the rain- and stormwater gives a 142 significant environmental advantage to A1 since electricity consumption for transport and treatment 143 of wastewater is reduced. The scale of the A1 alternative is smaller than the other alternatives as it 144 covers a smaller part of the city but could be expanded to the entire city including site specific 145 changes dependent on the architectural structure of the areas in the city. The environmental and 146 economic evaluations are calculated per $\mathrm{m}^{3}$ delivered water making the evaluations comparable 147 even though the scales differ. 


\subsubsection{Alternative A2: Compensating actions}

149 'Compensating actions' covers various initiatives implemented to meet the water flows in watercourses required as consequence of the implementation of the EU-WFD while maintaining the current groundwater abstraction. We considered compensating actions such as a) pumping of $590,000 \mathrm{~m} 3$ of groundwater and water from lakes per year to watercourses with low water flow and b) re-establishment of 18 hectares of wetlands from agricultural land (Supplementary material). The extent of compensating actions is based on the Danish EPA's guidelines to retain permissions for groundwater abstraction to meet Copenhagen's water demand. Besides the various compensating actions the alternative (A2) included all processes in the base alternative (A0).

\subsubsection{Alternative A3: New well fields}

The new well fields alternative is also equivalent to the base alternative but added a $20 \mathrm{~km}$ long pipeline from well fields to the waterworks while the distance is $5 \mathrm{~km}$ in the A0 alternative. The longer distance means increased energy consumption but new well fields $25 \mathrm{~km}$ from the waterworks are assumed to meet the requirements of the EU-WFD.

\subsubsection{Alternative A4: Desalination}

163 Copenhagen is situated at the entrance to the brackish Baltic Sea (Øresund) and desalination of 164 seawater is an option. The treatment plant is assumed to be located $5 \mathrm{~km}$ south of the city. The 165 processes of the plant consist of: mechanical filtration $(150 \mu \mathrm{m})$ to remove large particles; addition 166 of a coagulant; $\mathrm{pH}$ adjustment; ultra-filtration where $10 \%$ of the water is lost and returned to

167 Øresund after extraction of dry material; addition of anti-scaling; reverse osmosis desalination;

168 remineralization; and finally UV-treatment. The water hardness is designed to be $108 \mathrm{mg} / \mathrm{L}$ as $169 \mathrm{CaCO}_{3}$ when distributed (Rygaard, 2010). 
171 ASTA DSS was constructed to assist the decision maker in choosing the most sustainable 172 alternative within a given range of alternative solutions to a predefined problem. ASTA DSS

173 (Figure 2) divides the sustainability assessment into a hierarchy:

- First level has the 3 sustainability dimensions (environment, economy and society);

- Second level has in total 6 criteria within the dimensions

- Third level holds in total 13 indicators against which all alternatives are evaluated.

177 The three levels (dimensions, criteria and indicators) were chosen to break down the assessment

178 into indicators relevant to evaluate. For instance, for the environment dimension the criteria were 179 environmental, toxicity and resource impacts which are assessed through the impact categories of 180 the LCA (e.g. global warming potential, acidification, nutrient enrichment). The result is presented 181 with a total score and a bar chart showing the contribution from the 3 sustainability dimensions to 182 the total score. To make the decision transparent the scores can also be presented at the criteria level 183 (level 2) underlying each of the sustainability dimensions (level 1).

184 ASTA is based on 3 steps explained in the following.

\subsection{Step 1: Quantifying impacts at indicator level}

186 The impacts on the 3 dimensions of sustainability were quantified for the 13 indicators using 187 available tools for each sustainability dimension. Environmental impacts and economy were 188 quantified using life-cycle assessment and cost calculations. Societal indicators were quantified 189 from qualitative judgments by the use of an Analytical hierachy process (AHP). 


\subsubsection{Environmental indicators quantified by LCA}

191 The assessment of the sustainability dimension 'Environment' was assessed by the life-cycle assessment (LCA) tool where impacts on the environment (global warming, acidification, nutrient enrichment), on toxicity (eco toxicity via water and on human toxicity via water and soil) and resources are evaluated taking a life-cycle perspective on the alternatives. Inputs and emissions are included from the phases of extraction of raw materials through assembly, use and end-of-life treatment of all materials (Wenzel et al., 1997). The LCA of the base case and the 4 alternatives was performed according to the ISO 14044 standard procedure (ISO, 2006) with the GaBi 4.4 software delivered by PE International. The database from PE International was primarily used and when found insufficient the Eco-Invent database was used. Impacts were assessed by the EDIP 1997 method which is a standardized midpoint LCA method initially developed for the environmental development of industrial products (Wenzel et al., 1997) but also applicable for services such as drinking water supply (Godskesen et al., 2011). The EDIP method shares dominating many similarities with other life-cycle impact assessment (LCIS) methods e.g. ReCiPe, ILCD, TRACI 1.0 and 2, CML, but also some differences especially in the toxicity categories (Hauschild et al., 2018; Dreyer et al., 2003). As we use the LCA for comparison among alternative technologies for water supply we find the EDIP method applicable. A strength of the EDIP-method in our case is that the method is developed for the region of Europe. The normalized results of the midpoint method for Europe were calculated and used in the decision process (Godskesen et al., 209 2013).

210 In water production, water is the dominant resource consumed. In order to model the impacts of 211 abstracting freshwater we modified and applied a method originally aimed at assessing freshwater 212 withdrawal impacts (FWI) of industry on a regional scale (Lévová \& Hauschild, 2011) by 
213 converting to a local scale and basing the calculations on data on groundwater volumes (utilizable

214 volume and environmental freshwater requirements) from national regulations implementing the

215 EU-WFD (Godskesen et al., 2013). The FWI assessments of the 4 alternatives were used as a

216 measure for the criterium 'Resource impacts'.

217 The functional unit in the LCA was production of water which fulfilled the EU-WFD's water flow

218 requirements for water courses where freshwater was withdrawn and replacing $1 \mathrm{~m}^{3}$ of potable

219 drinking water as produced today. The produced water could be potable or non-potable depending

220 on the use of the drinking water that it replaces.

\section{$221 \quad$ 2.3.2 Economy indicator quantified by utility costs}

222 In the ASTA DSS the evaluation of economy is intended to be based on a cost-benefit analysis

223 (CBA) including costs of the utility regarding investment, operation and maintenance as well as

224 costs or benefits located in the society (Pearce et al., 2006) thereby making the system boundaries

225 equivalent to the LCA. However, due to limited access to data and to avoid additional uncertainty a

226 full cost-benefit analysis was not applied here. Instead, a partial life cycle cost analysis with focus

227 on the direct costs for the utility was conducted. This provided a means of combining investment

228 costs with ongoing costs into an annualized cost allowing for comparison across alternatives. Data

229 was based on the economic evaluation of projects similar to our alternatives carried out internally in

230 HOFOR (HOFOR, 2012). Thus, the system boundaries differs from the LCA where the effects in

231 the freshwater environments, at the consumers and wastewater treatment plant also were included.

232 The costs were calculated per $\mathrm{m}^{3}$ delivered making the alternatives comparable even though they do

233 not cover the same scale, e.g. supplying same amount of residents with water. 


\subsubsection{Societal indicators quantified by stakeholder workshop}

235 The LCA and economic evaluation were carried out by a specialist and resulted in direct

236 quantifications of impacts. Assessment of sustainability in the social dimension is inevitably

237 influenced by subjective judgments and statements. To convert the assessment of the social

238 dimension into quantitative scores, the indicators of the social dimension were assessed by

239 stakeholders at a workshop using the Analytical Hierarchy Process (AHP) (Saaty, 2006). The

240 workshop had 17 participants all related to the urban water supply (Table 1).

241 The 5 indicators in the social dimension were:

2) 'Aesthetics', which cover interpretation of the visual appearance of the system as well as perceived aesthetic acceptance

1) 'Acceptance of \& reliance on technology', i.e. the assumed public acceptance of the alternatives and the public confidence in the proposed technology implementation. In other words: a measure of the public trust in the system

3) 'Tourism \& contribution to water hub', where the assumed impact on tourism business was evaluated alongside the system's ability to attract international attention to local innovation within water technology

4) 'Political independency, i.e. the alternative's potential for increasing water self-sufficiency in the area and reducing dependency on regulators outside the municipality

5) 'Resilience', which covers the robustness, flexibility and adaptive capability of the system towards unpredictable or unforeseen events and developments, for example power outage, storms and climate change. There is no standard resilience assessment (Xue et al. (2015) but the stakeholders agreed on this explanation which they agreed on at the workshop. 
Indicators 1 to 3 belong to the criterion 'Customer values' and indicator 4 and 5 belong to criterion 'Applicability \& demand'.

In AHP, preferences between $n$ alternatives were determined by pair-wise comparisons for one indicator at a time resulting in a score $x_{i j}$ measuring the importance or dominance of alternative $i$ over alternative $j$. The comparison score was determined using the verbal value scale (Saaty, 2006) consisting of 5 verbal evaluations of importance or dominance and their intermediates (Figure 3). For each pair-wise comparison the stakeholders agreed on a verbal score describing the dominance or importance of one alternative over the other and assigned the associated value as the score $x_{i j}$. The scores were inserted in a decision matrix of the AHP method:

$\begin{array}{ccccc}\text { indicator }_{x} & \text { Alternative }_{1} & \text { Alternative }_{2} & \cdots & \text { Alternative }_{n} \\ \text { Alternative }_{1} & 1 & x_{12} & \cdots & x_{1 n} \\ \text { Alternative }_{2} & x_{21} & 1 & \cdots & x_{2 n} \\ \vdots & \vdots & \vdots & \ddots & \vdots \\ \text { Alternative }_{n} & x_{n 1} & x_{n 2} & \cdots & 1\end{array}$

266 The relative score of each alternative was found by calculating the geometric mean,

$267 \quad G_{i}=\sqrt[n]{x_{i 1} \cdot x_{i 2} \cdot \ldots \cdot x_{i n}}$, of each row in the decision matrix.

268 To evaluate the consistence of the AHP method, it provides an inconsistency index $=$

$269 \frac{\text { average ratio- } n}{n-1}$ for each set of judgments (set of all scores in a decision matrix). $n$ is the number of

270 alternatives and the average ratio is the average of the sums of each row in the decision matrix

271 divided by the weight of the criteria (Goodwin \& Wright, 2009). A low index indicates consistency 272 of the judgments of each alternative, however a low index is not the goal of the process. As a rule of 273 thumb the inconsistency index should be less than 0.1 when comparing 4 or more alternatives 
274 (Goodwin \& Wright, 2009). If the index was above 0.1 the judgments were reassessed and adjusted 275 accordingly if agreed upon among the stakeholders.

\subsection{Step 2: Weighting of indicators, criteria and sustainability dimensions}

277 In the second step each indicator's relative contribution to each criterion was calculated as the sum

278 of weighted indicator scores. Then weights were assigned to the individual criteria and

279 sustainability dimensions in a stakeholder workshop.

\subsubsection{Weighting of indicators}

281 For indicators in the society dimension, the importance was assumed to be equal and they were 282 weighted equally. The environmental indicators were weighted according to the LCA methodology 283 (Wenzel et al., 1997), and criteria with just 1 indicator per criteria, i.e. economy and resource 284 impacts, only weighting of indicators was needed.

\subsubsection{Weighting of criteria and sustainability dimensions in the stakeholder workshop}

286 The stakeholder workshop scoring of societal indicators also assessed the stakeholders' views on 287 the importance of sustainability dimensions and underlying criteria. The weights of the sustainability dimensions and criteria were determined by the ranked order distribution (ROD) method (Roberts \& Goodwin, 2002). Prior to the workshop we had predefined 3 sets of rank ordering where respectively environment, economy or society was given the highest rank. The

291 stakeholders were asked to form 3 groups matching their first priority of sustainability dimension and were given 20 minutes to negotiate an agreement on the rank of the remaining 2 dimensions and the rank of each criterion within each of the 3 dimensions. The predefined sets of rank ordering made it easier to reach the final rank order. Finally, ROD weights (Table 2) were assigned to each sustainability dimension or criterion as suggested for this type of rank ordering (Roberts \&

296 Goodwin, 2002). 


\subsection{Step 3: Combining results of indicators with the additive model}

298 In the third step, the results of dimensions and criteria are combined using an additive model based 299 on weighted sums. This procedure leads to the final evaluation of the proposed alternatives.

300 The indicator results in the ASTA DSS are reported on different scales and in different metrics. To 301 facilitate their comparison, we introduced an internal normalization step where each indicator result 302 or score for each alternative was divided by the sum for this indicator across all 4 alternatives. The 303 normalization step converted the results to a common scale for all indicators of the ASTA DSS and 304 lead to scores expressed as a proportion of the sum of all scores on a specific criterion and is a 305 commonly used procedure for normalization in MCDA (Rowley et al., 2012). Hereby we 306 considered the study on a local scale consisting of the 4 involved alternatives.

307 ASTA DSS is built on the principles of an additive weighted sum model. By adding the 308 contribution from each indicator for each alternative we obtain the total score (Goodwin \& Wright, 309 2009) of the alternatives. This means that the next step was to multiply each alternative's 310 normalized scores by the weights of the indicators and summed to arrive at the score for each

311 criterion. Then the criteria scores were multiplied by the weights elicited for the criteria and 312 summed to give the score for each sustainability dimension and finally these scores were multiplied 313 by the weights for the sustainability dimensions and summed to arrive at an overall sustainability 314 score for each alternative:

$$
\text { Total score }=\sum_{i=1}^{n}\left(\mathrm{w}_{i} \mathrm{~s}_{i}(a)\right)
$$


316 where $w$ is the weight and $s$ is the score of the $i$ 'th sustainability dimension, criteria or indicator of

317 alternative $a$. The Total score is an addition of the scores (wiøsi) of the indicators, criteria and

318 sustainability dimensions.

\section{$319 \quad 2.5 .1 \quad$ Inverting negative impacts}

320 A high total score in ASTA DSS means a preferable performance. To integrate all scores of

321 indicators, the reciprocal values of the LCA weighted impacts, resource impacts and costs were

322 normalized so that a high value in the LCA, FWI or costs calculations resulted in a low contribution 323 to the total score of the ASTA DSS. 


\section{Results \& Discussion}

\subsection{Environment}

For the environment dimension the alternative A1 'Rain- $\&$ stormwater harvesting' achieves the highest score within all 3 criteria: total environmental impacts; total toxicity impacts; and resource impacts (FWI) (Table 3). A1 has the highest scores of total environmental (0.369) and toxicity impacts (0.356) due to the prevention of the rain being discharged directly into the combined sewers, and avoiding its treatment at the wastewater treatment plant. A1 also obtains a high score due to the lower hardness of the rain- and stormwater which has positive effects in the households such as longer service life of washing machines and toilets, and lower electricity and laundry detergent consumption when washing clothes (Godskesen et al., 2012). The alternative A4 'Desalination of seawater' obtained the lowest score for environmental (0.151) and toxicity impacts (0.168) due to the high energy requirements of the desalination processes. The difference between A4 and the groundwater based alternatives A2 and A3 was relatively low, mainly due to the positive effects of reduced hardness of the desalinated water. For the groundwater based alternatives, the scores of total environmental and toxicity impacts were between A1 and A4. However, a previous study showed that water production from groundwater was environmentally preferable compared to other technologies for drinking water production such as membrane treatment of lake water, artificial recharge of groundwater or desalination of seawater (e.g. as in A4) (Godskesen et al., 2011). At the indicator level A4 'Desalination' performed better than the groundwater based alternatives A2 and A3 for the indicators ecotoxicity water and human toxicity water, which can be explained by reduced effects of hardness e.g. lower consumption of laundry detergent and increased service life of domestic appliances leading to lower consumption of materials. 
347 The A1 and A4 alternatives both obtained much higher scores on FWI $(0.636 ; 0.362)$ than the

348 alternatives with groundwater abstraction (0.001). The use of rainfall or seawater scored high (A1

349 and A4) on this indicator in contrast to the groundwater based water supplies (A2 and A3) since

350 these rely on the freshwater resource considered of high value and in scarcity in some regions

351 (European Environment Agency, 2012; Gleick, 2009).

\subsection{Economy}

353 Cost was estimated for investment, operation and maintenance and expressed in Euro per $\mathrm{m}^{3}$ water 354 delivered to the household. A1 Rain \& stormwater harvesting were markedly costlier at $3.8 € / \mathrm{m}^{3}$ 355 than the other alternatives ranging from 0.4 to $1.1 € / \mathrm{m}^{3}$ (Figure 4 ). The high cost of rain and 356 stormwater harvesting is mainly due to high investment costs in relation to a relatively low amount 357 of produced water. The normalized scores of the assessment of the economy showed that alternative 358 A2 Compensating actions is preferable (0.480) followed by A3 New well fields (0.286) and A4 359 Desalination (0.182) (Table 3).

\subsection{Society}

361 Selected results are shown in the following. Complete dataset from the stakeholder workshop is 362 available from the corresponding author.

\subsubsection{Society - indicator level}

364 As an example of the AHP method we present the detailed result of indicator 1) 'Acceptance \& 365 reliance on technology' within the criterion 'Customer values'. The 17 stakeholders reached 366 consensus on A2 'Compensating actions' had a strong to very strong importance over A1 'Rain \& 367 stormwater harvesting'. This verbal score results in a numerical value of 6, which implies that A2 368 has a 0.17 importance over A1. All the alternatives were judged against each other and the 369 geometric mean and normalized scores were calculated (Table 4). The procedure resulted in 18 
geometric means 0.34 for $\mathrm{A} 1$ and 3.22 for $\mathrm{A} 2$, and normalized scores of 0.059 for $\mathrm{A} 1$ and $0.557 \mathrm{~A} 2$

371 for the indicator 1) 'Acceptance \& reliance on technology'. These results implied that A2

372 'Compensating actions' is seen as the most sustainable alternative considering the indicator 1)

373 'Acceptance \& reliance on 'technology'. The procedure was similar for the 4 remaining social

374 indicators.

\subsubsection{Society - criteria level}

For the criterion 'Customer values', alternative A2 'Compensating actions' obtained the highest score on all 3 indicators (Table 3: $0.557 ; 0.564 ; 0.375$ ). For the indicator 'tourism \& contribution to water hub', stakeholders expressed that groundwater abstraction such as compensating actions were something that we in Denmark have experience and knowledge on and therefore have a strong potential for development and innovation through compensating actions. The desalination (A4) and rain- \& stormwater (A1) alternatives got generally low scores on the indicators under the "customer values" criterion except for 'Tourism \& contribution to water hub' where A1 obtains the highest score together with A2 (0.375).

The A4 alternative got high scores on the criterion 'Applicability \& demand', in particular because this alternative is independent from other authorities of the area such as municipalities who also have an interest in the area's groundwater ( 0.406 on the political independency indicator) and shows strong resilience regardless of e.g. predicted drought effects of global warming (0.504 on the resilience indicator).

The inconsistency index was below 0.1 for all indicators, except 2) 'Aesthetics', where the inconsistency ratio was 0.21 . This indicates a general consistency of the society indicator judgments across the alternatives, except for 'Aesthetics', which may be explained by a possible ambiguous perception of that specific indicator. 


\subsection{Assigning weights to sustainability categories and criteria}

394 Each of the three stakeholder teams had a set of rank ordering and weights for the sustainability 395 dimensions and criteria. Set 1 represented the stakeholder team assigning the highest weight to the 396 sustainability dimension environment; Set 2 to economy; and set 3 to society (Table 5). ROD 397 weights (Table 2) were assigned to the 3 dimensions with the most important dimension receiving 398 the weight 0.5232 , the second 0.3240 and the third 0.1528 .

399 It is noteworthy that regardless the set of weights applied, freshwater withdrawal impact was 400 identified as the most important among the environmental criteria (Table 5). This demonstrated the 401 high perceived importance of freshwater consumption and is in agreement with the focus of 402 politicians and researchers as expressed today in policy reports (European Environment Agency, 403 2012), European regulations (European Union, 2000) and the strong research interest in integrating 404 freshwater consumption into the LCA methodology (Pfister et al., 2009; Tendall et al., 2013).

\subsection{The ASTA-model}

\subsubsection{Total score results with 3 sets of weights}

407 We designed and carried out the ASTA-DSS including choosing the criteria in collaboration with 408 the utility. The sustainability criteria in this study were chosen to support the evaluation of 409 alternatives for planning future water supply systems for Copenhagen. The criteria are found 410 equivalent to other sustainability assessments based on various metrics (Xue et al., 2015; Rygaard 411 et al., 2014).

412 With the weighting of all indicators, criteria and dimensions in place, the total sustainability score 413 of each alternative was calculated with each of the 3 sets of weights. Figure 5 shows the results 414 subdivided on the underlying sustainability criteria. When the highest weight was assigned to 415 environment the alternative A1 'Rain- \& stormwater harvesting' obtained the highest total score 20 
(0.34) and was the most sustainable alternative according to the ASTA-model. However, at the stakeholder workshop many stakeholders expressed concerns regarding risk management, especially when it comes to people's health and the costs of A1 'Rain- \& stormwater'. A risk assessment of the alternatives could be a way to address the concerns for health and risk management in the alternatives, for example related to cross connections or risk of pollutants entering the potable water system, but this was not included here.

A1 was followed by A4 'Desalination' (0.28) due to the high weight given to 'Applicability \& demand' and the relatively low weight assigned to socio economy and costs by the stakeholders who weighted the environmental dimension of sustainability highest.

For stakeholders weighing economy or society highest the most sustainable alternative was alternative A2 'Compensating actions' $(0.34 ; 0.33)$ followed by either A1 'Rain- \& stormwater harvesting' $(0.22 ; 0.27)$ or A4 'Desalination' $(0.23 ; 0.22)$. For the economy set of weights, A2 dominated the other three alternatives which obtained very similar total scores. For the society set

429 of weights A2 also dominated but the alternatives were more differentiated with the alternative A1 430 scoring higher than A4 which scored higher than A3. Here, the A4 Desalination alternative became 431 the second most sustainable alternative mainly due to high weight of 'freshwater withdrawal impact', 'resilience' and 'political independency'.

433 For all 3 sets of weighting the alternative A3 'New well fields' had the lowest total scores (0.14;

$4340.21 ; 0.18)$ and was thereby the least sustainable option, regardless the applied stakeholder 435 perspective. In this way, the ASTA DSS emphasized that new well fields further away from the city 436 of Copenhagen is not the path to choose from a sustainability viewpoint. 


\subsubsection{Evaluation of workshop}

438 The workshop was a convenient and structured way of scoring indicators of the society dimension 439 and assigning weights by using the 2 suggested multi-criteria decision aid methods, AHP and ROD. 440 Especially the ROD method was easily applicable as the stakeholders simply should rank the 441 sustainability dimensions and criteria by order and not assign a specific value or weight to each 442 criterion (or dimension). The participating stakeholders were very motivated, knowledgeable and 443 covered a broad range of viewpoints from NGO's over public administration and utilities to 444 knowledge institutions (Table 1). The main challenge was to reach agreements when conducting the 445 AHP and ROD analyses. Consensus was reached after some discussions, and therefore the results 446 appear relatively robust.

447 According to the ASTA DSS the assessment of the sustainability dimensions 'Environment' and 448 'Economy' does not involve stakeholder participation and it was therefore performed in advance 449 which allowed for the result of the ASTA DSS to be given immediately at the workshop. It 450 motivated the participants knowing the results would be presented at the end of the workshop.

451 'Environment' and 'Economy' were evaluated by specialist whereas 'Society' was evaluated at the 452 stakeholder workshop. Our experience with mixing the specialist and workshop evaluations, 453 confirmed this procedure to be both convenient and transparent method for combining multiple 454 criteria in a holistic assessment.

455 The workshop also gave the opportunity to exchange viewpoints on the technologies, and the 456 discussions among the stakeholders at the workshop showed a preference for groundwater 457 abstraction such as promoted by A2' Compensating actions'. Groundwater abstraction is a field of 458 well-established experience and knowledge among the stakeholders and they felt that development 459 and innovation should be focused on this field for our region. 


\subsubsection{Decision support aid}

461 The result is now ready for use by decision makers who can determine which weighting set to select

462 for the final weighting for the decision support material - or which weights require further

463 development before they can be applied. Also the transparency of the cumulated results showing

464 contribution from individual criterion (Figure 5) provides help for the decision maker to document

465 why a certain alternative is the most sustainable alternative. As for Copenhagen's water supply

466 these results have supported implementation of compensating actions in combination with existing

467 groundwater abstraction. Our findings have also led to illustration of the positive effects of

468 softening water and central softening was introduced in summer 2017 for the first time in Denmark.

469 This underlines the importance of decision support aid and for the first time in our region a DSS, in

470 our case the developed ASTA DSS, is used to promote changes in the urban water system.

471 We selected a set of criteria and their coherent evaluation tool (e.g. environmental impacts - LCA)

472 which we together with the water utility considered relevant and essential to evaluate with the

473 purpose to identify the most sustainable alternative. This is in accordance with Xue et al. (2015)

474 who argue for the importance of developing decision support systems combining various criteria to

475 holistically evaluate the complete water system. Also Schoen et al. (2017) evaluated various criteria

476 (cost, energy, global warming, eutrophication and local human health) to identify the most

477 sustainable community water and sanitation service. In another study for Copenhagen Rygaard et

478 al. (2014) sets up similar criteria (cost, LCA impact categories, freshwater withdrawal impacts, risk

479 assessment, water self-sufficiency, demonstration value, resilience, etc ) to evaluate the most

480 sustainable option. In comparison, the ASTA DSS integrates the assessments of the criteria in to

481 one sustainability score by applying weighting. This makes the decision making more transparent

482 and easier to convey the assessments. 
483

484 


\section{Conclusion}

486 The development of the Decision Support System aimed at Assessing the most SusTainable 487 Alternative (ASTA DSS) and its application supported identification of the most sustainable future 488 supplementary water supply technology for Copenhagen. Based on this experience we conclude:

- The ASTA DSS generated a decision support incorporating three sustainability dimensions (environment, economy and society) leaving the decision maker with transparent and wellargued results making the decision easy to communicate. It also gave the decision maker the possibility of changing weights e.g. by identifying three sets prioritizing either of the sustainability categories highest to demonstrate the robustness of the decision.

- A stakeholder workshop was a convenient and structured way of involving all relevant stakeholders in providing weights for the sustainability categories and the criteria of the ASTA DSS and also for assessing the social indicators in a robust way, preparing for a broader acceptance and robustness of the results and the decisions based on them.

Of four suggested alternatives for Copenhagen water supply we found that

- When the highest weight was assigned to the 'Environment' dimension of sustainability, then the A1 alternative of 'Rain- \& stormwater harvesting' was the most sustainable followed by A4 'Desalination'.

When the highest weight was assigned to the 'Economy' or 'Society' dimension then the most sustainable alternative was A2 'Compensating Actions' followed by either A1 'Rain\& stormwater harvesting' or A4 'Desalination'.

- Regardless which sustainability dimension was given highest weight alternative A3 New well fields came out with the lowest sustainability score. 


\section{Acknowledgements}

508 We wish to thank: The Ministry of Science, Technology and Innovation in Denmark for funding the 509 industrial $\mathrm{PhD}$ under which this research was done; HOFOR for investing time and money in the $510 \mathrm{PhD}$, The Urban Water Tech Graduate School where the PhD candidate was a member; Lisbet 511 Brusendorff for improving the graphics; The participants at the stakeholder workshop August $17^{\text {th }}$ 5122012 and Michael Bruhn Barfod from DTU Transport for assisting with keeping track of the 513 evaluations and consistency of the judgements during the workshop. 


\section{References}

516 Alcamo J., Gallopín G. (2009). Building a 2nd generation of world water scenarios, UNESCO. The world water assessment programme. ISBN 978-92-3-104115-0.

518 Danish Nature Agency (2011). Vandplan 2010-2015 (eng.: River Basin Management Plan 2010519 2015). Isefjord og Roskilde Fjord. Hovedopland 2.2. Vanddistrikt Sjælland. ISBN nr. 978-87-7279$520 \quad 361-0$.

Dreyer L. C., Niemann A. L \& Hauschild M. Z. (2003). Comparison of Three Different LCIA Methods: EDIP97, CML2001 and Eco-indicator 99. Int J Life Cycle Assess. 8(4), 191-200.

European Environment Agency (2012). Towards efficient use of water resources in Europe, ISSN 1725-9177, Copenhagen, Denmark.

European Environment Agency (2007). Water Stress in Europe, 2000 and 2030

European Union.(2000). The Water Framework Directive (Directive 2000/60/EC of the European

Parliament and of the Council of 23 October 2000 establishing a framework for Community action 529 in the field of water policy).

530 Gleick P. H. (2009). The World's Water 2008-2009 / The biennial report on freshwater resources. 531 Island Press, Washington,DC.

532 Godskesen B., Hauschild M. Z., Rygaard M., Zambrano K. C. \& Albrechtsen H. J. (2013). Life533 cycle and freshwater withdrawal impact assessment of water supply technologies. Water research. 47(7), 2363.

Godskesen B., Hauschild M. Z., Rygaard M., Zambrano K. C. \& Albrechtsen H. J. (2012). Life management. 105, 83-89.

538 Godskesen B., Zambrano K. C., Trautner A., Johansen N. B., Godskesen B., Rygaard M., 539 Albrechtsen H. J., Johansen N. B., Thiesson L., Andersen L., Clauson-Kaas J., Neidel T. L., 540 Andersen L., Clauson-Kaas J., Neidel T. L. \& Kløverpris N. H. (2011). Life cycle assessment of 541 three water systems in Copenhagen-a management tool of the future. Water Sci Technol. 63(3), $542565-572$.

543 Goodwin P, Wright G (2009) Decision Analysis - for Management Judgment. In: Wiley, A John 544 Wiley and Sons, Ltd., Publication, The Atrium, Southern Gate, Chichester, West Sussex, PO19 545 8SQ, United Kingdom. 
Hajkowicz S. \& Collins K. (2007). A Review of Multiple Criteria Analysis for Water Resource Planning and Management. Water Resour Manage. 21(9), 1553-1566.

Halog A. \& Manik Y. (2011). Advancing Integrated Systems Modelling Framework for Life Cycle Sustainability Assessment. Sustain (Switzerland). 3(2), 469-499.

Hauschild M., Rosenbaum K. R., Olsen S. I. (2018). Life Cycle Assessment - Theory and Practice. Chapter 40. Springer. ISBN 978-3-319-56475-3 (eBook).

HOFOR (2012). Personal communication: data from internal document on price for alternative scenarios for supplying Copenhagen with water compared to the existing drinking water production and wastewater treatment, spring 2012.

ISO (2006). Environmental management - Life Cycle Assessment - Requirements and guidelines ISO 14044, ISO 14044:2006, European Committee for Standards, rue de Stassart, 36, B-1050 Brussels.

Jaber J.,O.\&Mohsen M.,S. (2001). Evaluation of non-conventional water resources supply in Jordan. Desalination. 136(1-3), 83-92.

Jensen A. V., Ambrasaite I., Salling K. B., Barfod M. B. \& Leleur S. (2012). The EcoMobility Modelling Framework for Sustainable Transport Planning. Rethinking Transport in the Øresund Region. 149-164.

Jensen M. B. (2009). Basisrapport: Dobbeltporøs filtrering. Pilotafprøvning - Rensning af vejvand i Ørestad. Hændelse 1-25, januar - juli 2007 (eng.: Double Porous Filter - Pilot project). Copenhagen University. Denmark.

Lai E., Lundie S. \& Ashbolt N. J. (2008). Review of multi-criteria decision aid for integrated sustainability assessment of urban water systems. Urban Water Journal. 5(4).

Lévová T. \& Hauschild M. Z. (2011). Assessing the impacts of industrial water use in life cycle assessment. CIRP annals. 60(1), 29-32.

Lundie S., Peters G., Ashbolt N., Lai E. \& Livingston D. (2006). WATER RESOURCES - A Sustainability Framework for the Australian Water Industry - The best of current strategic planning and sustainability assessments. Water. 33(7).

Makropoulos C. K., Natsis K., Liu S., Mittas K. \& Butler D. (2008). Decision support for sustainable option selection in integrated urban water management. Environmental Modelling and Software. 23(12), 1448-1460.

Milà-i-Canals L., Chapagain A., Orr S., Chenoweth J., Anton A. \& Clift R. (2010). Assessing freshwater use impacts in LCA, part 2: case study of broccoli production in the UK and Spain. Int J Life Cycle Assess. 15(6), 598-607. 
Muñoz I., Mila-i-Canals L. \& Fernández-Alba A. R. (2010). Life Cycle Assessment of Water Supply Plans in Mediterranean Spain: The Ebro River Transfer Versus the AGUA Programme. $J$ Ind Ecol. 14(6), 902-918.

Navarrete M. C., Olmedo G. J., Valsero D. J. J., Gómez G. J. D., Espinar L. J. A. \& Orden G. (2008). Groundwater protection in Mediterranean countries after the European water framework directive. Environ Geol. 54(3), 537-549.

Pearce D, Atkinson G, Mourato S (2006) Cost-Benefit Analysis and the Environment. In: OECD, Paris, France, pp 318.

Pfister S., Koehler A. \& Hellweg S. (2009). Assessing the environmental impacts of freshwater consumption in LCA. Environmental Science and Technology. 43(11), 4098-4104.

Roberts R. \& Goodwin P. (2002). Weight approximations in multi-attribute decision models. Journal of Multicriteria Decision Analysis. 11(6), 291-303.

Rowley H. V., Peters G. M., Lundie S. \& Moore S. J. (2012). Aggregating sustainability indicators: Beyond the weighted sum. J Environ Manage. 111, 24-33.

Rygaard M. (2010). Desalinated water in urban water supplies - a systems approach to identify optimal drinking water composition. PhD Thesis, Technical University of Denmark (DTU Env).

Rygaard M., Albrechtsen H. and Binning P. J. (2009). Alternative water management and selfsufficient water supplies. IWA Publishing, London.

Rygaard M., Godskesen B., Jørgensen C. \& Hoffmann, B. (2014). Holistic assessment of a secondary water supply for a new development in Copenhagen, Denmark. Science of the Total Environment. 497-498. 430-439.

Saaty T. L. (2006). Fundamentals of decision making and priority theory / with the analytic hierarchy process. RWS Publications, Pittsburgh, PA.

Schoen M. E., Xiabo X., Wood A., Hawkins T. R., Garland J. \& Ashbolt N. J (2017). Cost, energy, global warming, eutrophication and local human health impacts on community water and sanitation service options. Water Research. 109, 186-195.

Sombekke H. D. M., Voorhoeve D. K. \& Hiemstra P. (1997). Environmental impact assessment of groundwater treatment with nanofiltration. Desalination. 113(2-3), 293-296.

UN, 2015. Sustainable development goals - 17 goals to transform our world. http://www.un.org/sustainabledevelopment/sustainable-development-goals

UNEP (1992) Rio Declaration on Environment and Development. In: United Nations Publication.

US Geological Survey (2012). Water hardness and alkalinity, http://water.usgs.gov/owq/hardnessalkalinity.html. 
611 van Zelm R., Schipper A. M., Rombouts M., Snepvangers J. \& Huijbregts M. A. J. (2010).

612 Implementing Groundwater Extraction in Life Cycle Impact Assessment: Characterization Factors

613 Based on Plant Species Richness for the Netherlands. Environ Sci Technol. 45(2), 629-635.

614 WCED (1987) World Commission on Environment and Development, the so-called Brundtland 615 report, Our common future. In: New York: Oxford University Press.

616 Wenzel H, Hauschild MZ, Alting L (1997) Environmental asessment of products - 1: Methodology, 617 tools and case studies in product development. In: Kluwer Academic Publishers, Hingham, MA.

618 USA, Chapman \& Hall, United Kingdom.

619 Xue X., Schoen M. E., Ma X., Hawkins T. R., Ashbolt N. J., Cashdollar J. \& Garland J. (2015).

620 Critical insights for a sustainability framework to address integrated community water services:

621 Technical metrics and approaches. Water Research. 77. 155-169.

622

623

624

625

626

627 


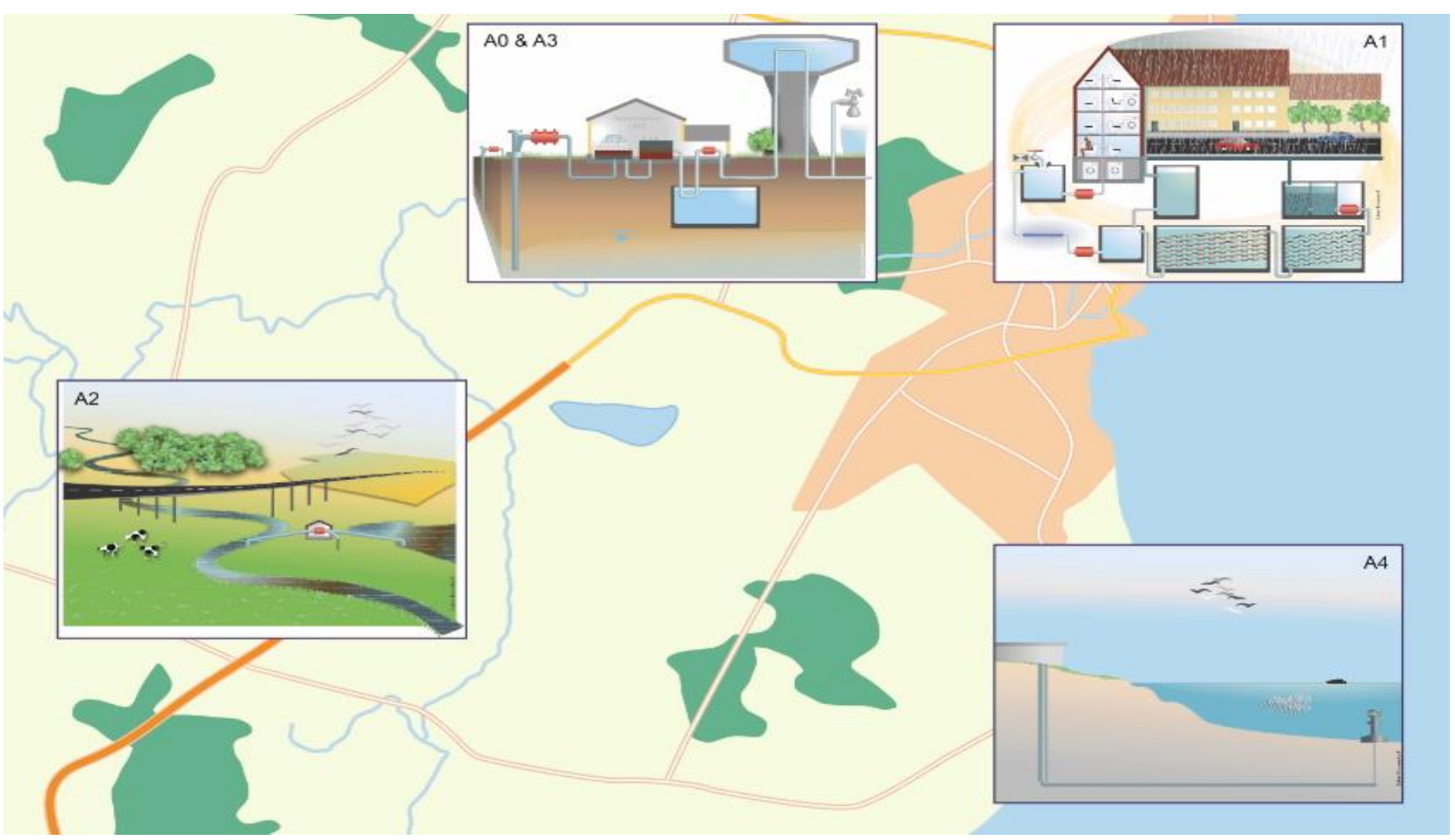

631 Figure 1. The 4 alternatives and base case included in this study: A0 'Base alternative' relying on 632 groundwater abstraction; A1 'Rain- \& stormwater harvesting'; A2 'Compensating actions' 633 consisting of water transfer in the affected catchment areas; A3 'Establishing new well fields' 20

$634 \mathrm{~km}$ further away from the waterworks; A4 'Desalination of seawater from Øresund'. The

635 background is a map illustrating where the alternative is located in relation to the urban area (dark 636 orange). 


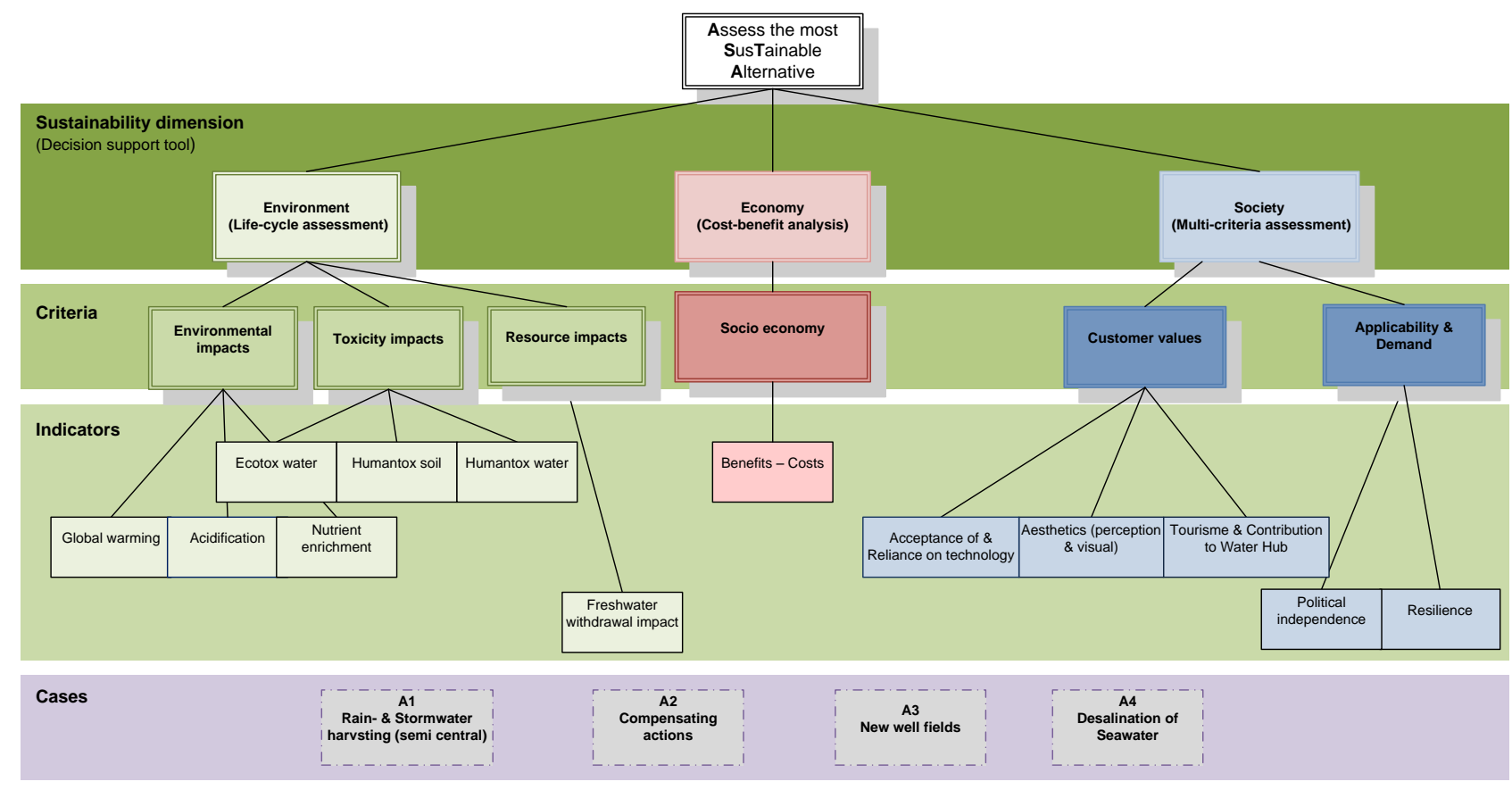

641 Figure 2. The decision hierarchy of how to assess the most sustainable alternative - the ASTA-

642 model. The hierarchy contains three sustainability dimensions (environment, economy and society) 643 and three levels (dimensions, criteria and indicators).

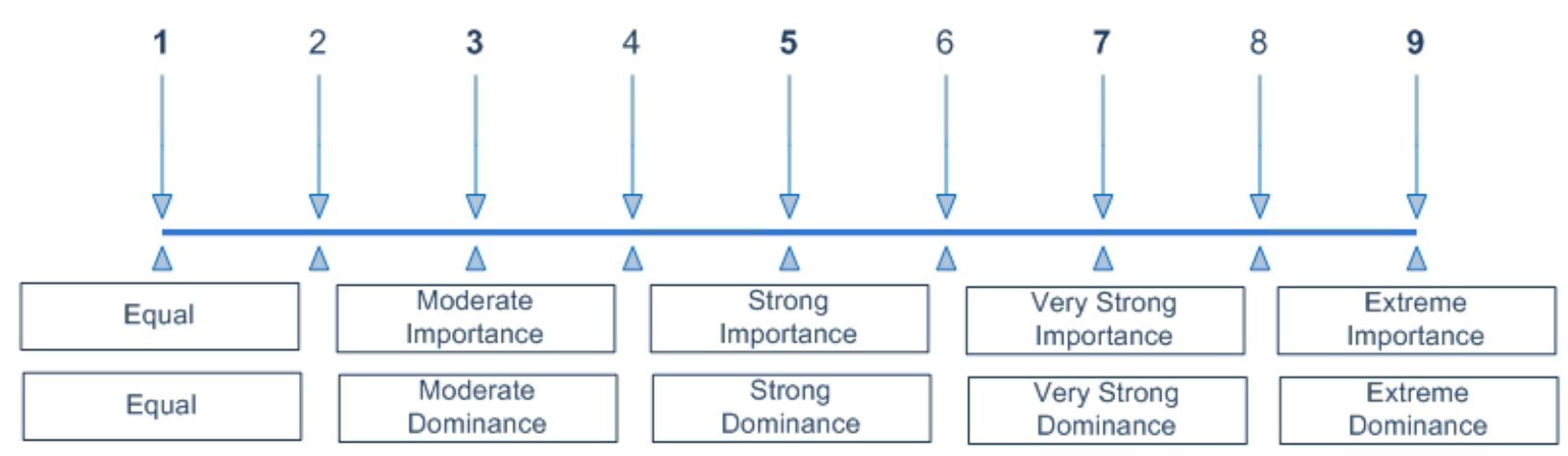

646 Figure 3. Saaty's 9 value scale (modified from Saaty, 2006) consisting of 5 verbal evaluations (1, 3,

6475,7 and 9) and their intermediates of importance or dominance when comparing one alternative

648 over the other. 


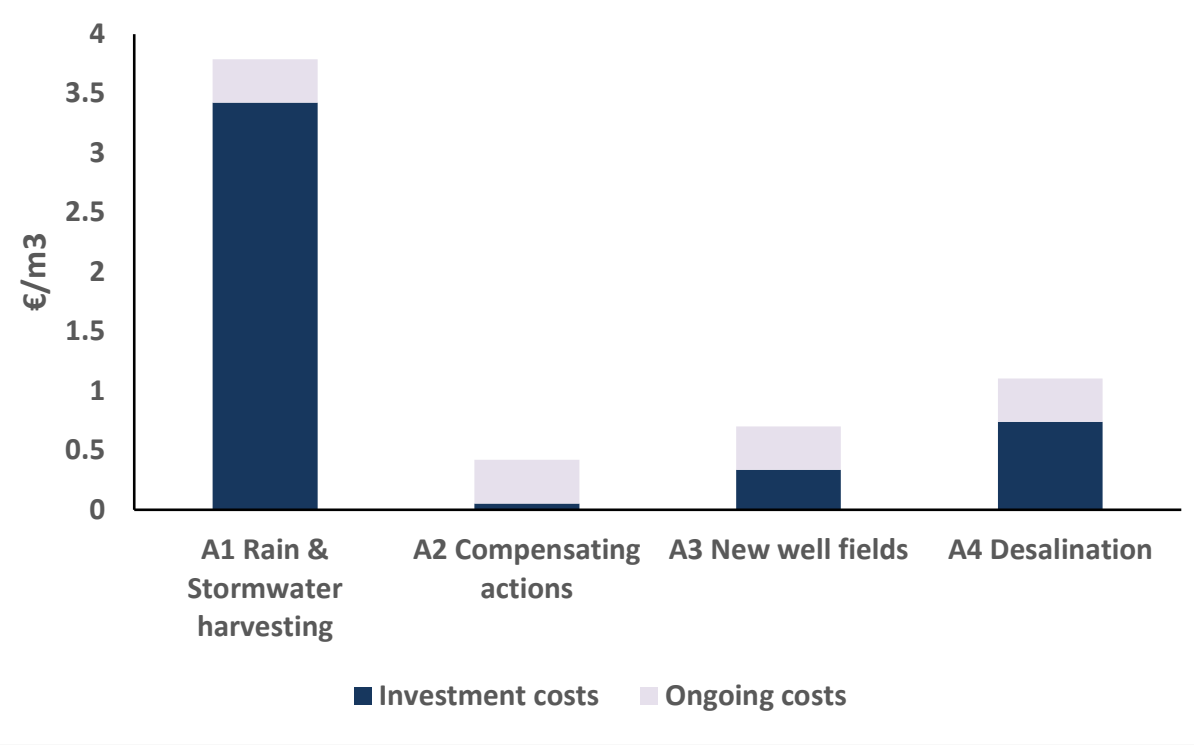

651 Figure 4. Estimated investment, operation and maintenance cost of the four investigated 652 alternatives.

653

654 


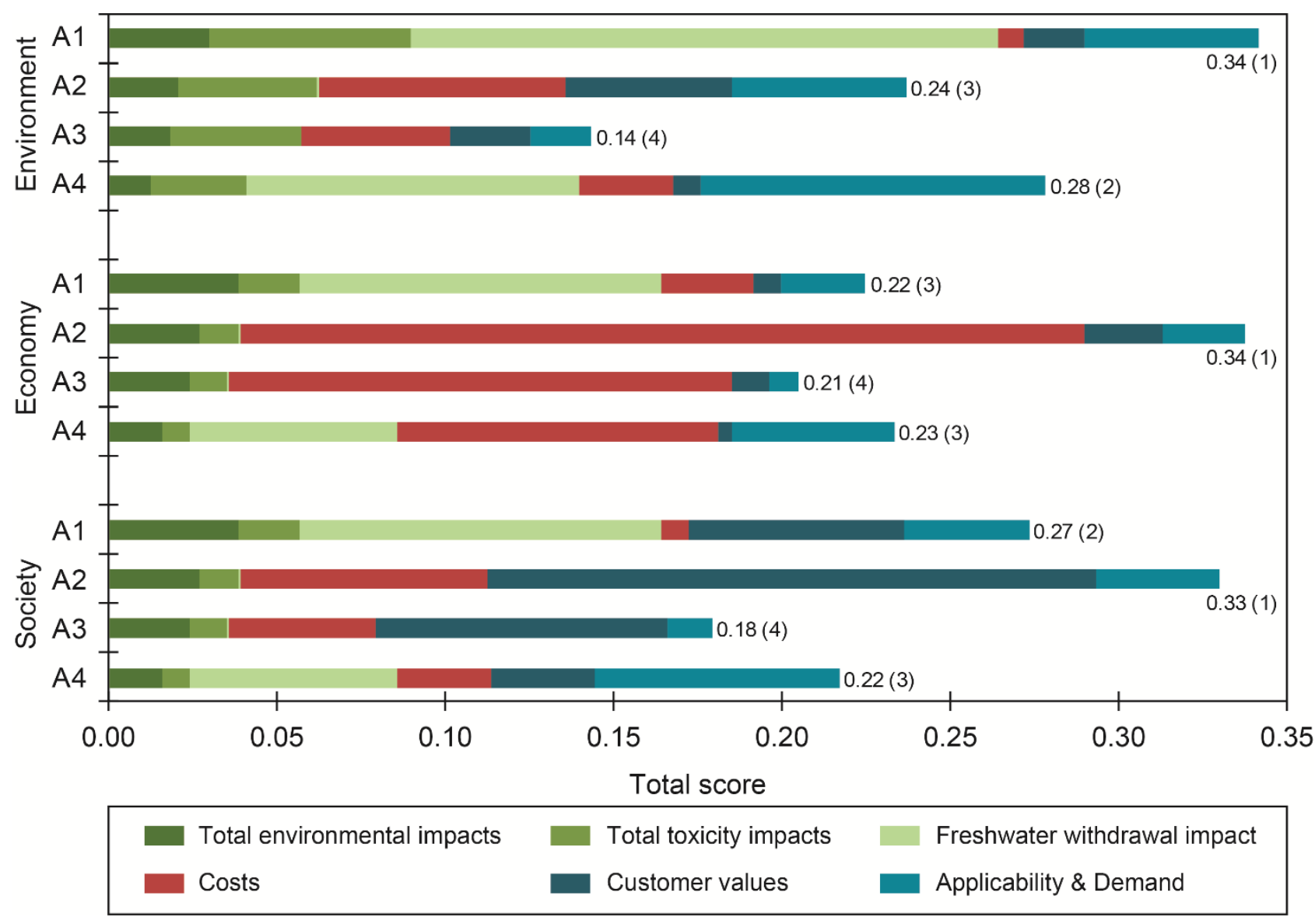

656 Figure 5. The total scores from the multi-criteria assessment of the four alternatives combining the

657 results for the 6 criteria: Total environmental impacts; Total toxicity impacts; Freshwater

658 withdrawal impact; Costs; Customer values and Applicability \& demand. The 3 sets of bars

659 represent each of the stakeholder teams with the highest ranked Sustainability dimension being

660 environment, economy or society respectively.

661

662

663

664

665

666 
List of Abbreviations

\begin{tabular}{ll}
\hline AHP & Analytical hierarchy process \\
ASTA & $\underline{\text { Assess the most sustainable alternative }}$ \\
CBA & Cost-benefit analysis \\
DSS & Decision support system \\
EU-WFD & European Union's Water Framework Directive \\
FWI & Freshwater withdrawal impact \\
LCA & Life-cycle assessment \\
MCDA & Multi-criteria decision analysis \\
ROD & Rank order distribution
\end{tabular}


676 Table 1. List of participants of the Stakeholder Workshop.

Place of employment or representation

Number of

participants

The Danish Nature Agency (the authority implementing the EU-WFD)

3

The Danish Competition and Consumer Authority

The Danish Water and Wastewater Association

The Danish Water Forum

The Geological Survey of Denmark and Greenland

The Technical University of Denmark, Department of Environmental

Engineering

Consultancy in Environment and Construction

The Ecological Council, a Danish Non-governmental organization

Water customer

The water utility (HOFOR)

Total 
680 Table 2

681 Rank order distribution (ROD) weights (Roberts \& Goodwin, 2002)

\section{Number of Criteria}

$\begin{array}{rrrrrrrrrr}\operatorname{Rank} & 2 & 3 & 4 & 5 & 6 & 7 & 8 & 9 & 10\end{array}$

\begin{tabular}{|c|c|c|c|c|c|c|c|c|c|}
\hline 1 & 0.6932 & 0.5232 & 0.4180 & 0.3471 & 0.2966 & 0.2590 & 0.2292 & 0.2058 & 0.1867 \\
\hline 2 & 0.3068 & 0.3240 & 0.2986 & 0.2686 & 0.2410 & 0.2174 & 0.1977 & 0.1808 & 0.1667 \\
\hline 3 & & 0.1528 & 0.1912 & 0.1955 & 0.1884 & 0.1781 & 0.1672 & 0.1565 & 0.1466 \\
\hline 4 & & & 0.0922 & 0.1269 & 0.1387 & 0.1406 & 0.1375 & 0.1332 & 0.1271 \\
\hline 5 & & & & 0.0619 & 0.0908 & 0.1038 & 0.1084 & 0.1095 & 0.1081 \\
\hline 6 & & & & & 0.0445 & 0.0679 & 0.0805 & 0.0867 & 0.0893 \\
\hline 7 & & & & & & 0.0334 & 0.0531 & 0.0644 & 0.0709 \\
\hline 8 & & & & & & & 0.0263 & 0.0425 & 0.0527 \\
\hline 9 & & & & & & & & 0.0211 & 0.0349 \\
\hline 10 & & & & & & & & & 0.0173 \\
\hline
\end{tabular}

682 
684 Table 3. Scores from the assessment of the 4 alternatives. Values were normalized against the total 685 score of the four alternatives to reflect the relative contribution to a total score of 1 at the criteria 686 and indicator level respectively. A high value was considered positive for the evaluation of the 687 alternative.

\begin{tabular}{|c|c|c|c|c|c|c|}
\hline $\begin{array}{l}\text { Sustainability } \\
\text { dimensions }\end{array}$ & Criteria & Indicators & $\begin{array}{l}\text { A1 Rain\& } \\
\text { stormwater }\end{array}$ & $\begin{array}{c}\text { A2 } \\
\text { Compensating } \\
\text { actions }\end{array}$ & $\begin{array}{c}\text { A3 } \\
\text { New } \\
\text { well } \\
\text { fields }\end{array}$ & $\begin{array}{c}\text { A4 } \\
\text { Desali- } \\
\text { nation }\end{array}$ \\
\hline \multirow[t]{7}{*}{ Environment } & $\begin{array}{l}\text { Environmental } \\
\text { impacts** }\end{array}$ & & 0.369 & 0.253 & 0.227 & 0.151 \\
\hline & & Global warming ${ }^{* *}$ & 0.340 & 0.269 & 0.243 & 0.148 \\
\hline & & Acidification** & 0.474 & 0.198 & 0.177 & 0.151 \\
\hline & & $\begin{array}{l}\text { Nutrient } \\
\text { enrichment** }\end{array}$ & 0.425 & 0.223 & 0.200 & 0.152 \\
\hline & $\begin{array}{l}\text { Toxicity } \\
\text { impacts** }\end{array}$ & & 0.356 & 0.247 & 0.229 & 0.168 \\
\hline & & $\begin{array}{l}\text { Ecotoxicity } \\
\text { water** }\end{array}$ & 0.469 & 0.165 & 0.152 & 0.214 \\
\hline & & $\begin{array}{l}\text { Human toxicity } \\
\text { soil** }\end{array}$ & 0.303 & 0.307 & 0.274 & 0.116 \\
\hline
\end{tabular}




\begin{tabular}{llllll}
\hline & Human toxicity & 0.294 & 0.200 & 0.202 & 0.304 \\
& & & & \\
& water** & & & \\
Resource & & & & & \\
impacts & & & & & \\
& & & & & \\
& Freshwater & 0.636 & 0.001 & 0.001 & 0.362 \\
& withdrawal & & & & \\
& impact* & & &
\end{tabular}

Economy Socio economy

Benefits - costs*

0.052

0.480

0.286

0.182

Society Customer values

Acceptance of \&

0.059

0.557

0.291

0.093

reliance on

technology

Aesthetics

0.096

0.564

0.303

0.037

(perception \&

visual)

Tourism \&

0.375

0.375

0.125

0.125

Contribution to

Water Hub

Applicability \&

Demand

Political

0.373

independence 
689 environmental and toxicity impacts, the score is based on the reciprocal of standardized distance to 690 political target-values (Person equivalent targeted, PET) incorporated in the Life-cycle assessment 691 (Wenzel et al., 1997).

692

693

694

695

696

697

698

699

700

701

702

703 
704 Table 4. The AHP decision matrix of the indicator Acceptance \& reliance on technology with 705 relative importance/dominance values as found in the stakeholder workshop using the verbal score 706 system (Figure 3.). Inconsistency ratio was 0.1 for this indicator.

\begin{tabular}{lllllll}
\hline A1 Rain & A2 & A3 New & A4 & Geometri & Normalize \\
& $\&$ & Compensatin & well & Desalination & c mean & d score \\
stormwate & g actions & fields & & \\
r & & & & & \\
& & & & & \\
harvesting & & & &
\end{tabular}

\begin{tabular}{lcccccc}
\hline A1 Rain \& & 1 & 0.17 & 0.25 & 0.33 & 0.34 & 0.059 \\
stormwater & & & & & & \\
harvesting & 6 & 1 & 3 & 6 & 3.22 & 0.557 \\
A2 & & & & & & \\
\end{tabular}

Compensating

actions

$\begin{array}{lllllll}\text { A3 New well } & 4 & 0.33 & 1 & 6 & 1.68 & 0.291\end{array}$

fields

$\begin{array}{lllllll}\text { A4 Desalination } & 3.00 & 0.17 & 0.17 & 1 & 0.54 & 0.093\end{array}$

707

708

709

710 
711 Table 5. Rank ordering of sustainability categories and Criteria for the 3 stakeholder teams and

712 determination of the associated three sets of weights by rank order distribution (ROD).

\begin{tabular}{llll}
\hline Sustainability & Set 1 & Set 2 & Set 3
\end{tabular}

Category Most important: Most important: Most important:

$\begin{array}{lll}\text { Criteria } & \text { environment society }\end{array}$

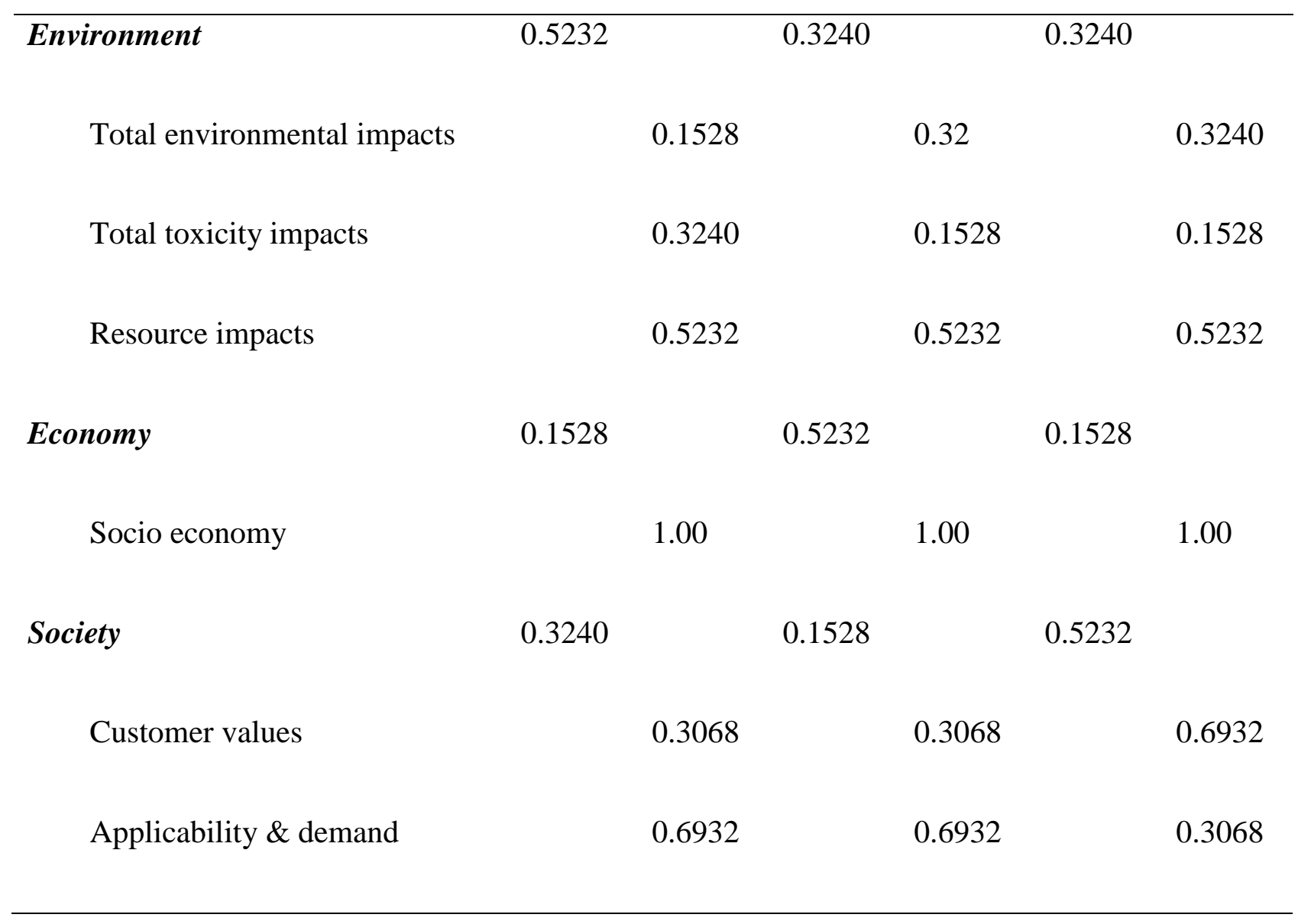

713 